\title{
AVALIAÇÃO DE INTERAÇÕES ENTRE QUEBRADORES E CLUSTERS EM FORNO DE REDUÇÃO DIRETA USANDO $O$ MÉTODO DOS ELEMENTOS DISCRETOS*
}

Fernando de Oliveira Boechat ${ }^{1}$ Rodrigo Magalhães de Carvalho ${ }^{2}$ Luís Marcelo Marques Tavares ${ }^{3}$

\section{Resumo}

As maiores pressões e temperaturas atualmente empregadas a fim de aumentar a produtividade de fornos de DRI têm resultado em um subproduto indesejado: o aumento da geração de clusters. Estes clusters prejudicam o fluxo da carga e a permeabilidade do leito. A fim de limitar o tamanho destes aglomerados o forno MIDREX dispõe de três conjuntos de quebradores localizados em diferentes posições do forno após a redução da carga. A interação entre clusters e esses quebradores, entretanto, pode também prejudicar o fluxo da carga e aumentar a geração de finos. O trabalho utilizou o método dos elementos discretos (DEM) para avaliar as energias e forças resultantes da interação entre os clusters formados e os quebradores. A descrição dos clusters foi realizada usando o bonded-particle model, disponível no EDEM. Simulações mostraram que a presença de clusters altera as forças e velocidades no entorno dos quebradores que tenderiam a aumentar a geração de finos no reator.

Palavras-chave: DEM; Quebradores; Cluster.

\section{ASSESSING INTERACTIONS BETWEEN CLUSTERS AND BURDENFEEDERS IN A DIRECT REDUCTION FURNACE USING THE DISCRETE ELEMENT METHOD}

\begin{abstract}
The higher pressures and temperatures currently used with the aim of increasing the productivity of DRI furnaces have resulted in an undesired byproduct: the increase in the generation of clusters. These clusters worsen of the flow of the internal charge of the furnace and the permeability of the bed. In order to limit the size of these clusters, the MIDREX furnace has three sets of burdenfeeders, located in different positions inside the furnace after the region of load reduction. The presence of large clusters near these burdenfeeders affect negatively the flow of charge and can increase fines generation. The present work used the discrete element method (DEM) to estimate the energies and forces resulting from the interaction of these clusters and the burdernfeeders. The clusters structure was simulated using the bonded-particle model, available in EDEM. Simulations showed that the presence of clusters alters the forces and velocities around burdenfeeders which would tend to increase the generation of fines in the reactor.
\end{abstract}

Keywords: DEM; Burdenfeeders; Cluster.

1 Engenheiro de Produção, M.Sc., Professor, Faculdade Católica Salesiana do Espírito Santo, ES, Brasil.

2 Engenheiro Químico, M.Sc., D.Sc., Professor Adjunto, Programa de Engenharia Metalúrgica e de Materiais, COPPE, Universidade Federal do Rio de Janeiro, RJ, Brasil.

3 Engenheiro de Minas, M.Sc., Ph.D, Professor Titular, Programa de Engenharia Metalúrgica e de Materiais, COPPE/UFRJ, Rio de Janeiro, RJ, Brasil. 


\section{INTRODUÇÃO}

Nos últimos anos, a produção de ferro esponja tem crescido no mundo e, entre os processos utilizados, o MIDREX, tem tido maior destaque, sendo responsável por mais de $60 \%$ da produção mundial [1]. O forno utilizado é do tipo cuba, o qual trabalha em contracorrente com os gases de redução. Ele pode ser dividido em três zonas: zona de redução, zona de transição e zona de resfriamento. Por ser um processo que utiliza o gás como agente redutor é importante que o fluxo dos gases seja uniforme. Alguns fatores podem interferir na homogeneidade do fluxo dos gases como, por exemplo, a presença de finos, a heterogeneidade da carga e a presença de clusters. Este último tem se tornado, nos últimos anos um dos principais problemas para os produtores de ferro esponja. Segundo Wong e colaboradores [2], o clustering e resultado das ligações criadas pelo crescimento de ferro fibroso na superfície do minério de ferro durante as etapas iniciais da metalização. $O$ aumento da temperatura dos reatores nos últimos anos é apontado como sendo um dos principais fatores para uma maior geração de clusters nos fornos MIDREX.

Para diminuir a tendência à colagem na carga metálica, é realizada a aspersão de um agente de recobrimento óxido refratário na carga ferrífera antes do seu carregamento. No entanto, este recobrimento é superficial e caso a carga não permaneça integra durante seu carregamento e redução, a formação de clusters será inevitável devido às regiões fragmentadas não terem este agente de recobrimento. Os clusters gerados na zona de redução irão seguir até a zona de transição e de resfriamento onde quebradores se encontram dispostos em três locais. Estes são projetados para oscilar através de ângulos pré-determinados com uma velocidade que é ajustada de forma a promover o movimento transversal uniforme da carga e limitar o tamanho dos aglomerados formados pela sua quebra. $O$ primeiro conjunto de quebradores se localiza imediatamente abaixo do local de injeção do gás redutor na zona de transição, enquanto os dois últimos e localizam abaixo do ponto de injeção de gás de resfriamento (Figura 1).

A presença de clusters na região destes quebradores irá afetar o fluxo da carga e poderá ser necessário aumentar a velocidade dos quebradores que poderá influenciar a geração de uma maior quantidade de finos na descarga do forno. A simulação computacional se apresenta como uma ótima ferramenta para otimizar a operação e a configuração desses quebradores. Assim, o presente trabalho analisa como a presença de clusters influencia o fluxo da carga e como influencia as forças e energias presentes nesta região através da utilização do modelo de elementos discreto (DEM). 


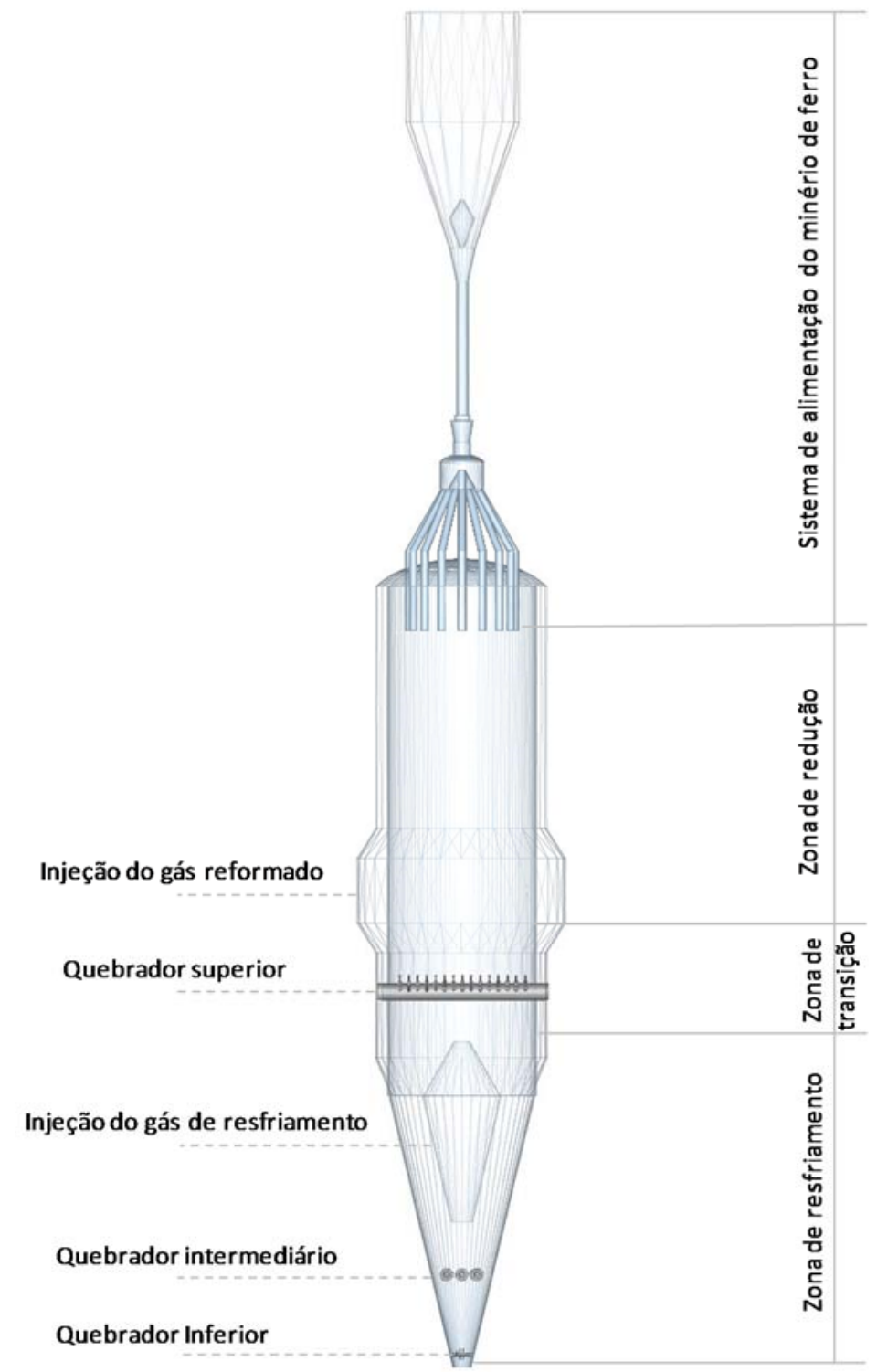

Figura 1. Forno de redução do processo MIDREX ${ }^{\circledR}$

\section{MATERIAIS E MÉTODOS}

Para a realização das simulações da região dos quebradores foi utilizado o software EDEM. O EDEM requer que vários parâmetros característicos das pelotas sejam informados, tendo sido utilizados os valores previamente obtidos em outro trabalho [3]. Os clusters foram criados considerando o bonded-particle model, ou seja, o qual é o modelo disponível no EDEM que permite simular agregados de partículas que podem ser fragmentados pela aplicação de esforços mecânicos. Entretanto, este modelo necessita de informações das energias de ligação entre as partículas que compõem o cluster. A fim de calibrar esses parâmetros do modelo foram comparados resultados de ensaios de tamboramento segundo a norma ISO 11256 [4] a resultados de simulações. Neste ensaio o cluster é submetido a 35 revoluções divididas em sete etapas. Nas simulações foi considerada apenas a primeira etapa, ou seja, apenas cinco revoluções (Figura 2). A simulação foi repetida, alterando os parâmetros de energia de ligação crítica para obter um valor no qual partes das pelotas permanecessem ligadas e partes se soltassem, pois esse foi o tipo de resultado obtido experimentalmente. 


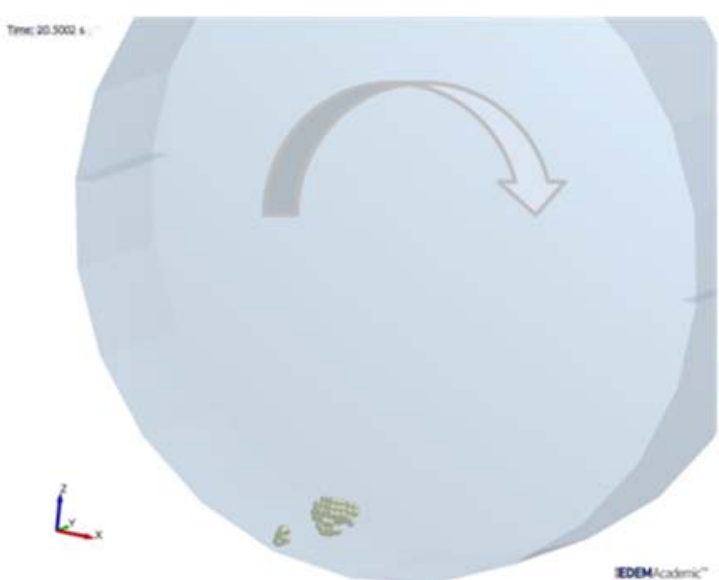

Figura 2. Simulação de clustering segundo norma ISO 11256

A partir dos parâmetros calibrados, foram criados clusters de dois tamanhos: um com tamanho pequeno o suficiente para passar facilmente pelo quebrador e outro com tamanho maior, de maneira que ficaria retido no quebrador (Figura 3).

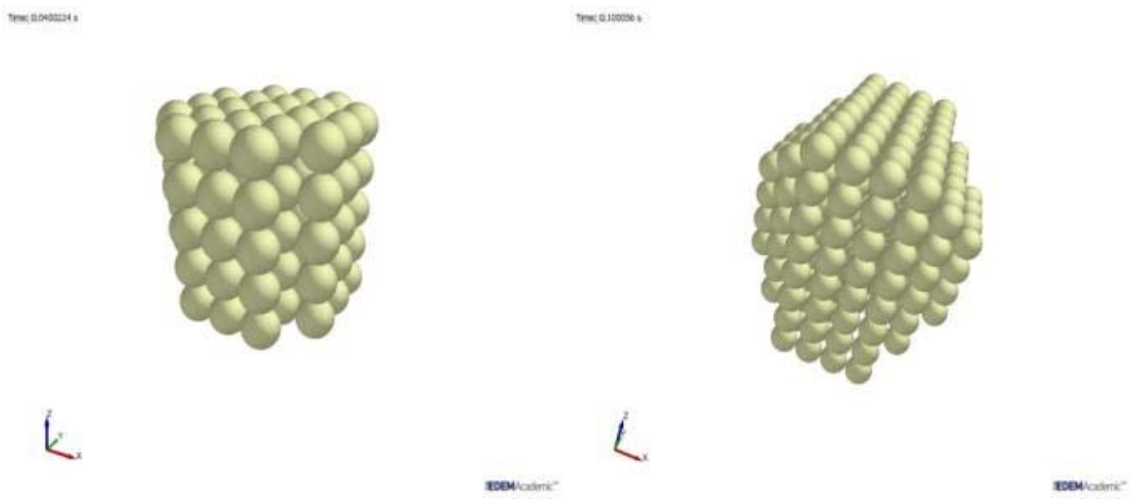

Figura 3. Formato dos clusters utilizados para simulações

A fim de minimizar o esforço computacional necessário para a realização das simulações, fez-se necessário adotar algumas premissas para construção do modelo de forma a diminuir o número de partículas envolvidas no processamento. Primeiramente as simulações tomaram como base um forno de redução MIDREX do tipo Minimod ${ }^{\circledR}$ [5] com capacidade aproximada de 500.000 toneladas ano e cujas dimensões são proporcionais aos fornos de maior capacidade. Foi escolhida a região do quebrador inferior para realização das simulações pois essa é a região com menor área, bem como pelo fato da carga já estar a uma temperatura mais próxima à ambiente. Outra premissa utilizada foi a de considerar os mesmos parâmetros de contato de DEM utilizados para carga não reduzida [3]. É importante lembrar que a carga ferrífera perde resistência mecânica ao ser reduzida [6] e essa informação deve ser ponderada na interpretação dos resultados encontrados.

A partir dessas várias premissas foi criado o modelo da região do quebrador inferior no $\operatorname{EDEM}^{\circledR}$ e foram inseridas as partículas (pelotas de minério de ferro) de forma a preencher toda a região do quebrador (Figura 4). As demais simulações foram realizadas a partir do reator preenchido com uma vazão aproximada de $16,5 \mathrm{~kg} / \mathrm{s}$ controlada por uma base virtual abaixo das partículas. Foi mantida uma criação de partículas na parte superior a uma taxa de $20 \mathrm{~kg} / \mathrm{s}$. Foram realizadas simulações com e sem a inserção de clusters para efeito comparativo. 

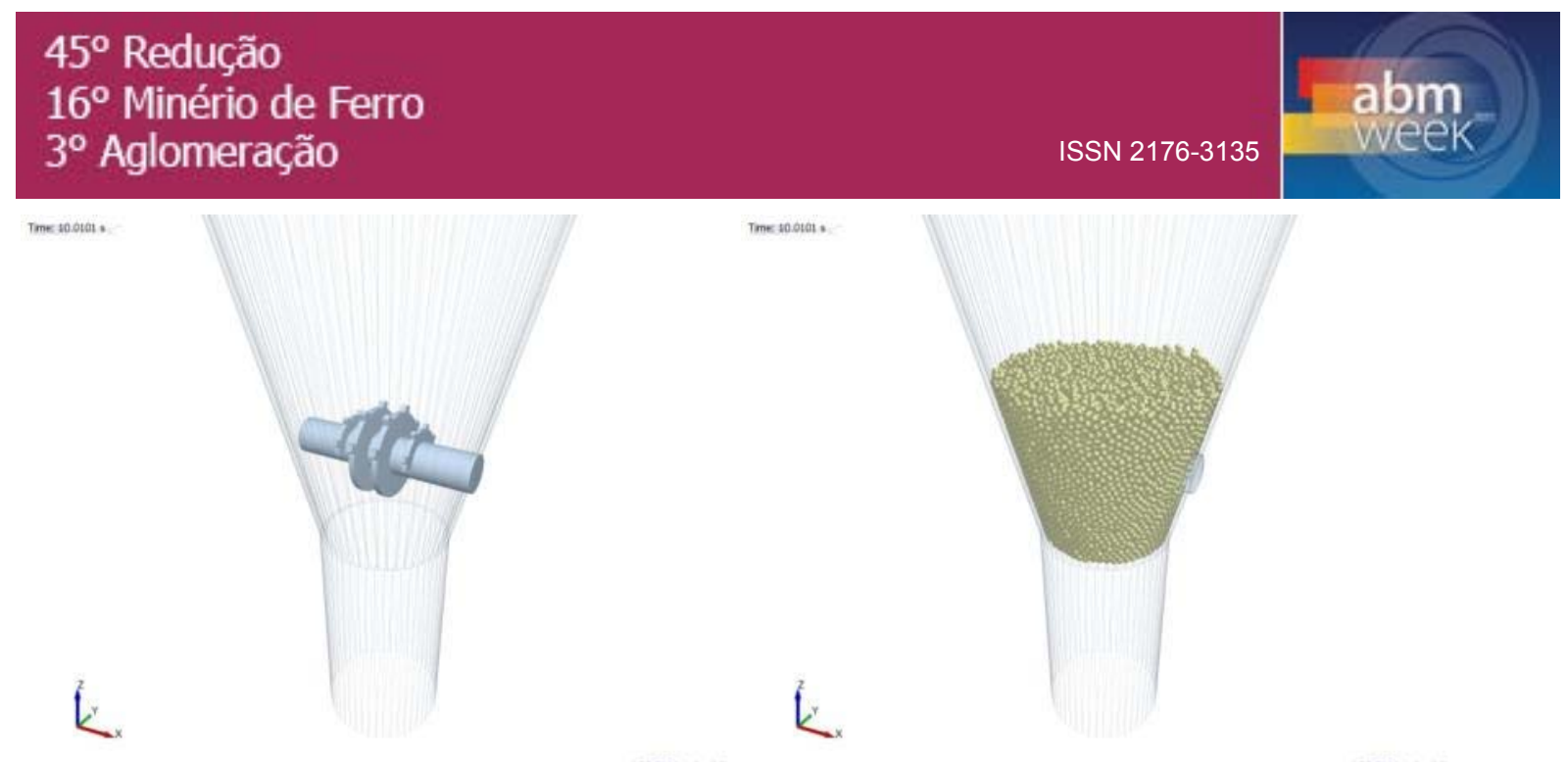

Figura 4. Região simulada sem e com partículas

\section{RESULTADOS E DISCUSSÃO}

A Tabela 1 apresenta um resumo dos cenários simulados na região do quebrador inferior do forno Midrex. A Simulação 01 refere-se àquela na qual o reator não possui clusters em seu interior e o quebrador apresenta velocidade de rotação constante. As forças compressivas são fracas e não apresentam valores capazes de fragmentar as pelotas, tomando como base a redução de $75 \%$ [6] na redução de uma pelota com $2800 \mathrm{~N} /$ pelota, ou seja, considerando valor para fragmentar as pelotas reduzidas superiores a $700 \mathrm{~N}$ (aproximadamente $70 \mathrm{kgf}$ ). Nas simulações 02 e 03 foram inseridos clusters de tamanho pequeno (capazes de passar pela menor abertura entre 0 quebrador e a parede do forno) e clusters grandes, respectivamente. Nestes dois casos percebe-se que algumas pelotas passam a sofrer com forças compressivas superiores a $700 \mathrm{~N}$. Na simulação 04 , os clusters foram inseridos em apenas um dos lados do forno e mostraram forças compressivas médias altas, mas não superiores àquelas alcançadas nas simulações anteriores. A fim de avaliar a influência da operação do quebrador foi realizada a simulação 05 , na qual foi aumentada a frequência de rotação do quebrador em $50 \%$. Na pratica, não foi observado nenhum aumento na força compressiva associado a isso. Assim, mantendo a mesma velocidade do quebrador foram adicionados clusters (simulação 06) e, diferente da simulação 05 , foi observada a maior média de força compressiva com valores chegando a superar $1000 \mathrm{~N}$. Apesar do aumento de velocidade não ter tido efeito significativo nas pelotas, o efeito combinado da taxa de alimentação e da velocidade do quebrador resultou em maiores valores de força compressiva na região do forno.

A Figura 5 apresenta a distribuição dos valores de força compressiva ao longo da região simulada. Pode-se verificar que entre as figuras $5 a$ e $5 e$ não há diferença na distribuição das forças compressivas, mostrando que a velocidade do quebrador não altera significativamente as forças compressivas envolvidas. Os maiores valores destes ensaios estão localizados na saída do reator, provavelmente provocados pela redução do diâmetro nesta área. A diferença entre o lado esquerdo e o direito da seção é provocada pelo movimento do quebrador. Na Figura $5 \mathrm{~b}$, os pequenos clusters inseridos se tornam pontos de acumulo de forças. Por outro lado, clusters grandes inseridos, além de serem pontos de maior força compressiva, provocam a retenção do material, como evidenciado na Figura $5 c, 5 d$ e $5 f$. Esta retenção resulta no aparecimento de uma região de baixa compressão logo abaixo destes clusters. 
Tabela 1. Resumo dos resultados dos diferentes cenários de simulação nas forças compressivas

\begin{tabular}{ccccccc}
\hline Simulação & $\begin{array}{c}\text { Média } \\
\text { (N) }\end{array}$ & $\begin{array}{c}\text { Máximo } \\
\mathbf{( N )}\end{array}$ & $\begin{array}{c}\text { Mediana } \\
\mathbf{( N )}\end{array}$ & $\begin{array}{c}\text { Desvio } \\
\text { Padrão (N) }\end{array}$ & $\mathbf{\%}>\mathbf{5 0 N}$ & $\mathbf{\%}>\mathbf{1 0 0 N}$ \\
\hline 01 & 12,5 & 178 & 8,5 & 13,0 & $2,0 \%$ & $0,05 \%$ \\
02 & 15,2 & 742 & 9,2 & 20,3 & $4,6 \%$ & $0,5 \%$ \\
03 & 15,6 & 924, & 9,0 & 23,2 & $5,1 \%$ & $0,8 \%$ \\
04 & 15,7 & 1158 & 9,8 & 21,9 & $4,6 \%$ & $0,6 \%$ \\
05 & 12,8 & 185,4 & 8,6 & 13,3 & $2,2 \%$ & $0,06 \%$ \\
06 & 20,2 & 1364 & 11,3 & 30,0 & $9,4 \%$ & $1,6 \%$ \\
\hline
\end{tabular}

Apesar do movimento do quebrador não ter efeito significativo na distribuição de forças compressivas na região estudada, quando se analisa a velocidade das pelotas no leito vemos que o quebrador passa a ter um efeito mais expressivo. Analisando a Figura 6a e 6c percebe-se que a velocidade padrão do quebrador mantém alguma uniformidade ao longo do eixo do forno. Entretanto quando aumentada em $50 \%$ a velocidade, percebe-se que o sentido do giro do quebrador causa um maior deslocamento das pelotas do lado esquerdo. A presença de clusters (Figuras 6b, 6c, 6d e 6f) também afeta o fluxo das pelotas e por este motivo podem retardar ou aumentar a velocidade das partículas. No caso de clusters que ainda não entraram na região de quebra (entre o quebrador e as paredes do forno neste caso), percebe-se que ocorre uma redução na velocidade das pelotas situadas imediatamente acima dos clusters. Por outro lado, quando os clusters entram na região de quebra e começam a fragmentar, eles deixam espaços vazios que logo são ocupados pelas pelotas posicionadas imediatamente acima deles, aumentando a sua velocidade nesta região. A Figura $6 \mathrm{f}$ mostra que o aumento da velocidade de giro do quebrador aliada à presença de cluster aumenta a magnitude das velocidades nesta região do forno.

A Figura 7 apresenta a distribuição da energia de colisões no reator para as mesmas simulações apresentadas anteriormente, porém dando ênfase para as energias envolvidas. Para a condição considerada padrão $7 a$, percebe-se que as energias envolvidas nos choques são baixas e estão distribuídas de forma similar ao longo do eixo do forno. Comparando com $7 \mathrm{e}$, a simulação na qual a velocidade de giro do quebrador foi elevada em $50 \%$, percebe-se apenas um ligeiro aumento das energias de colisões sem que haja mudanças em sua distribuição. A inserção de clusters resultou em alteração no perfil das energias de colisões, sendo que a região onde estes se encontram apresentou maior magnitude das energias de colisão. A presença de clusters em apenas um lado do reator $7 \mathrm{~d}$ mostra que, além da maior energia na posição dos clusters, a energia do lado oposto também sofre um ligeiro aumento. Mais uma vez a interação entre a velocidade do giro do quebrador aumentada em $50 \%$ e a presença de clusters $7 \mathrm{f}$ mostrou ser mais impactante no aumento das energias de colisões envolvidas. 

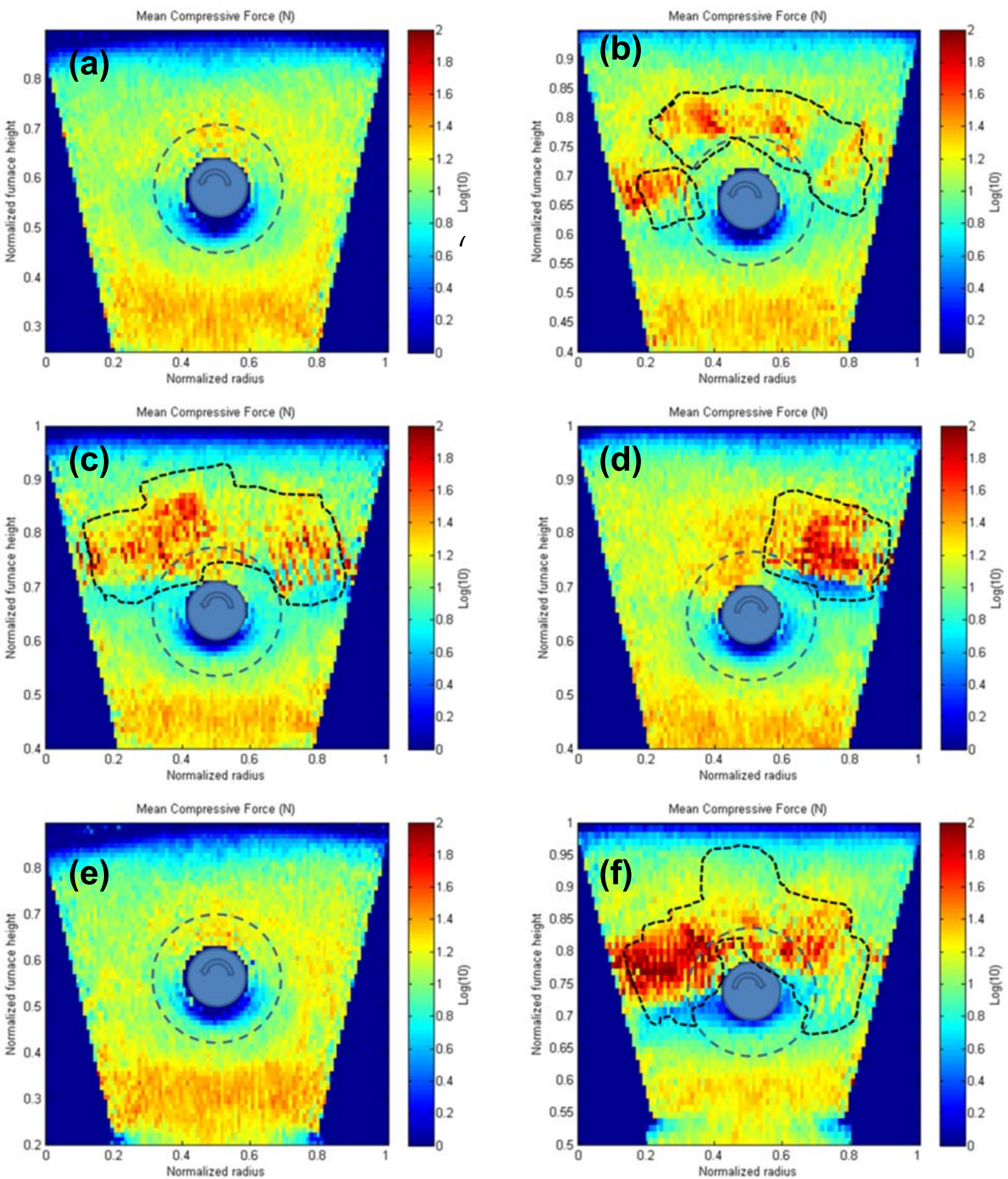

Figura 5. Força compressão média: a) Fluxo de partículas sem a presença de cluster (simulação 01) b) Fluxo de partículas com presença de cluster de tamanho pequeno (simulação 02); c) Fluxo de partículas com presença de cluster de tamanho grande (simulação 03); d) Fluxo de partículas com presença de cluster em apenas um lado do reator (simulação 04); e) Fluxo de partículas sem a presença de cluster com velocidade do quebrador aumentada em 50\% (simulação 05) e f) Fluxo de partículas com a presença de cluster com velocidade do quebrador aumentada em $50 \%$ (simulação 06). OBS: Região circular referente à posição do quebrador e região pontilhada preta referente à posição dos clusters no intervalo da análise. 

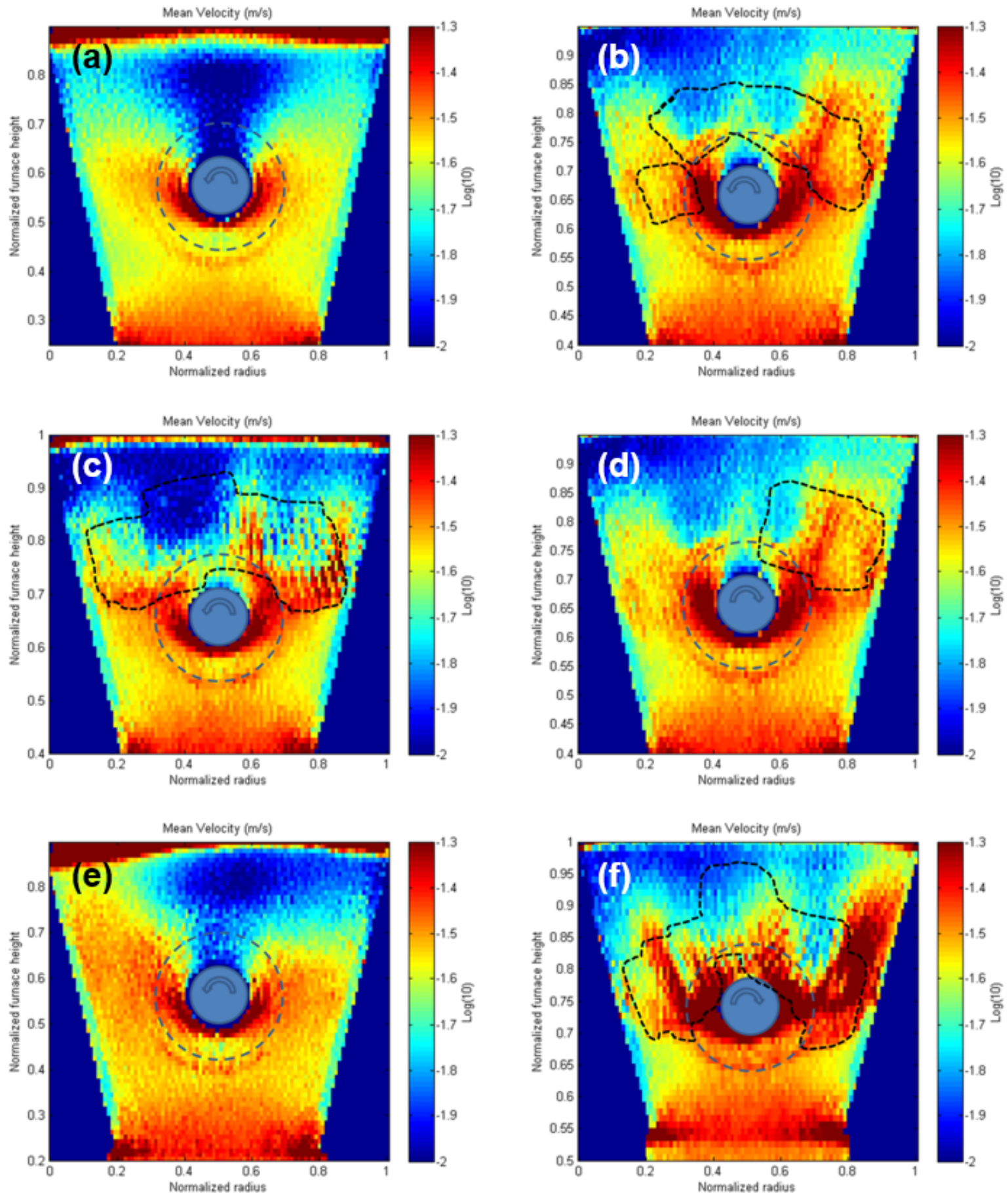

Figura 6. Velocidades médias das partículas: a) Fluxo de partículas sem a presença de cluster (simulação 01); b) Fluxo de partículas com presença de cluster de tamanho pequeno (simulação 02); c) Fluxo de partículas com presença de cluster de tamanho grande (simulação 03); d) Fluxo de partículas com presença de cluster em apenas um lado do reator (simulação 04); e) Fluxo de partículas sem a presença de cluster com velocidade do quebrador aumentada em $50 \%$ (simulação 05 ) e f) Fluxo de partículas com a presença de cluster com velocidade do quebrador aumentada em $50 \%$ (simulação 06). OBS: Região circular referente à posição do quebrador e região pontilhada preta referente à posição dos clusters no intervalo da análise. 

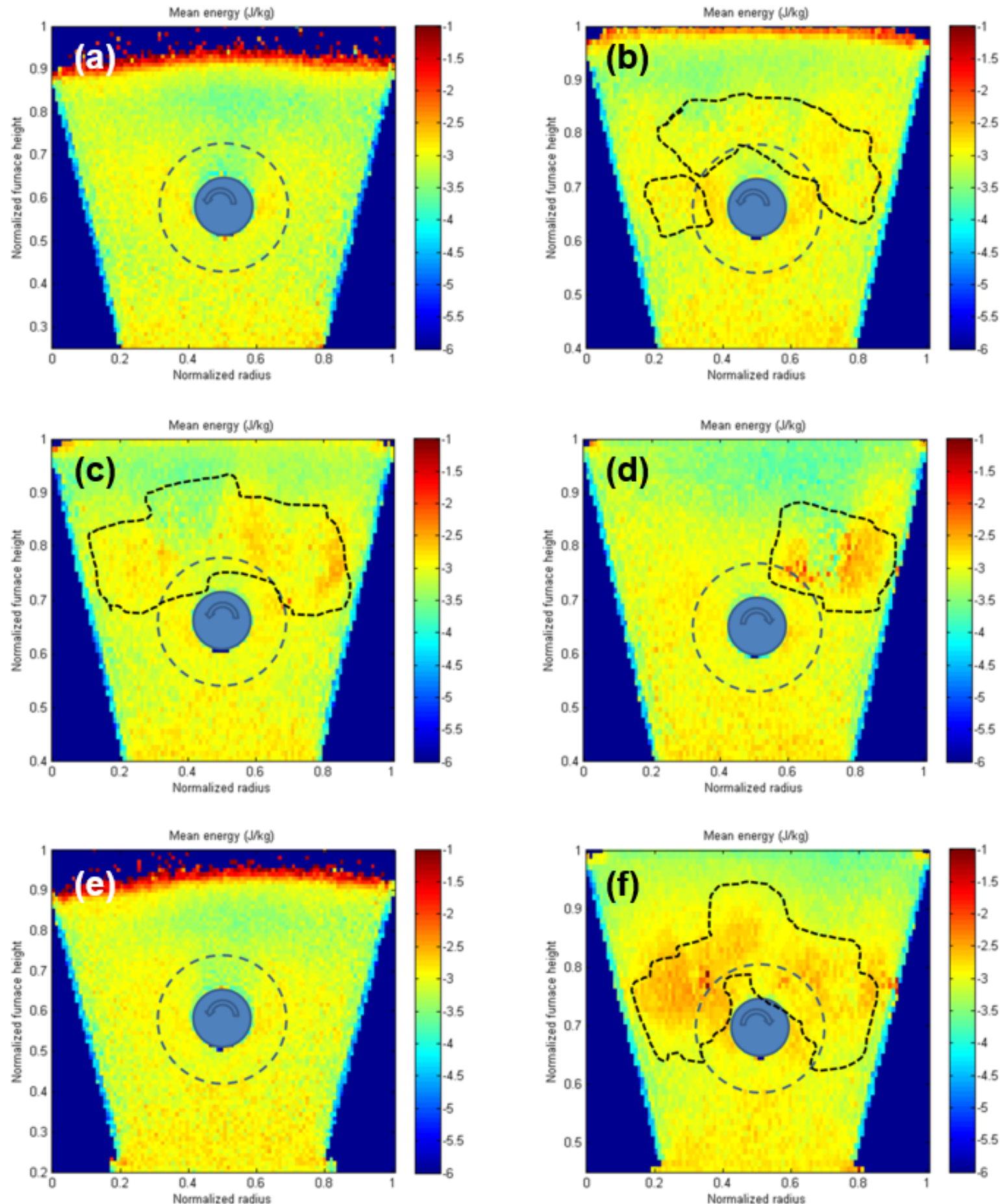

Figura 7. Magnitude e frequência da dissipação normal de energia de colisão: a) Fluxo de partículas sem a presença de cluster (simulação 01); b) Fluxo de partículas com presença de cluster de tamanho pequeno (simulação 02); c) Fluxo de partículas com presença de cluster de tamanho grande (simulação 03); d) Fluxo de partículas com presença de cluster em apenas um lado do reator (simulação 04); e) Fluxo de partículas sem a presença de cluster com velocidade do quebrador aumentada em $50 \%$ (simulação 05) e f) Fluxo de partículas com a presença de cluster com velocidade do quebrador aumentada em $50 \%$ (simulação 06).

Entretanto na simulação do movimento da carga no interior do reator observou-se que as energias dissipadas se mostraram insuficientes para gerar degradação das pelotas. Isto pode ser concluído com base o trabalho de Tavares e Carvalho [7] no qual precisaríamos de uma energia mediana na ordem de $102 \mathrm{~J} / \mathrm{kg}$ e considerando pelotas 
integras como alimentadas no forno. Por outro lado, calculando a geração de finos geradas por estas energias, baseada no trabalho de Boechat et al. [8], pode-se perceber que, mesmo sendo pequena, a geração de finos na região simulada tende a ter um aumento significativo quando da presença de clusters (Figura 8) aproximadamente da ordem de $33 \%$. Considerando, além da presença de cluster, o aumento da velocidade de giro do quebrador, a Figura 9 mostra que a geração de finos tende a mostra-se maior apresentando um valor mais significativo na produção do reator.

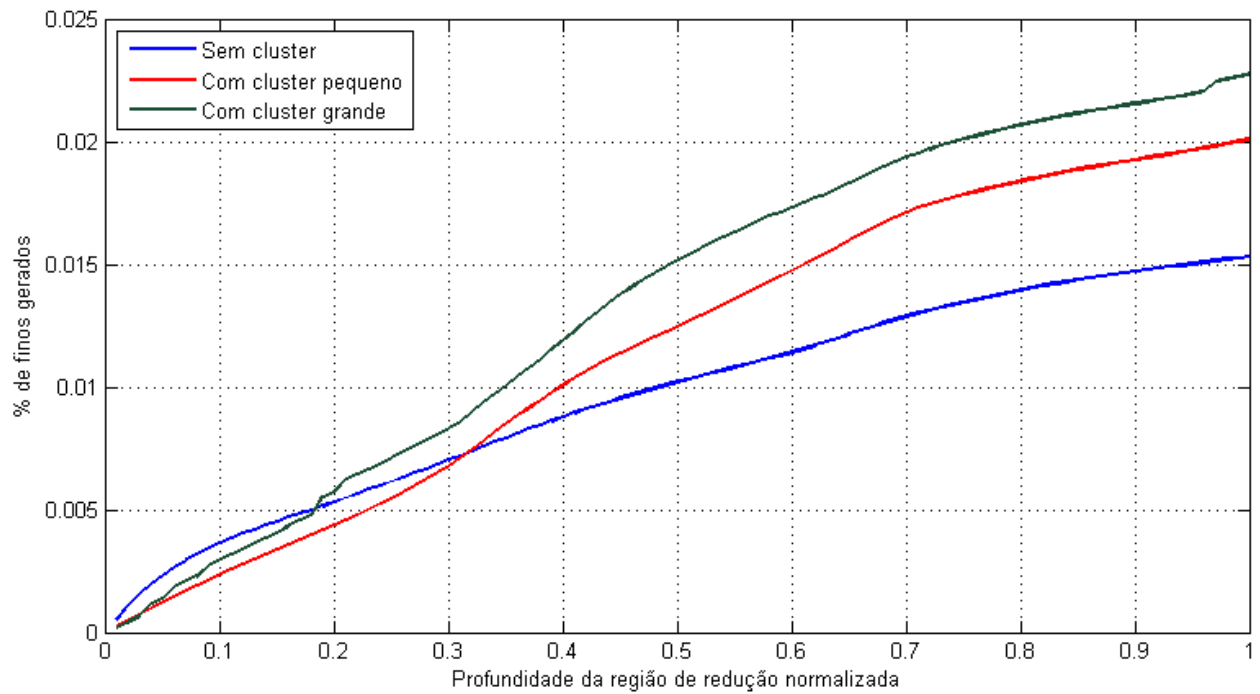

Figura 8. Evolução da geração de finos em relação à profundidade do forno na região do quebrador inferior.

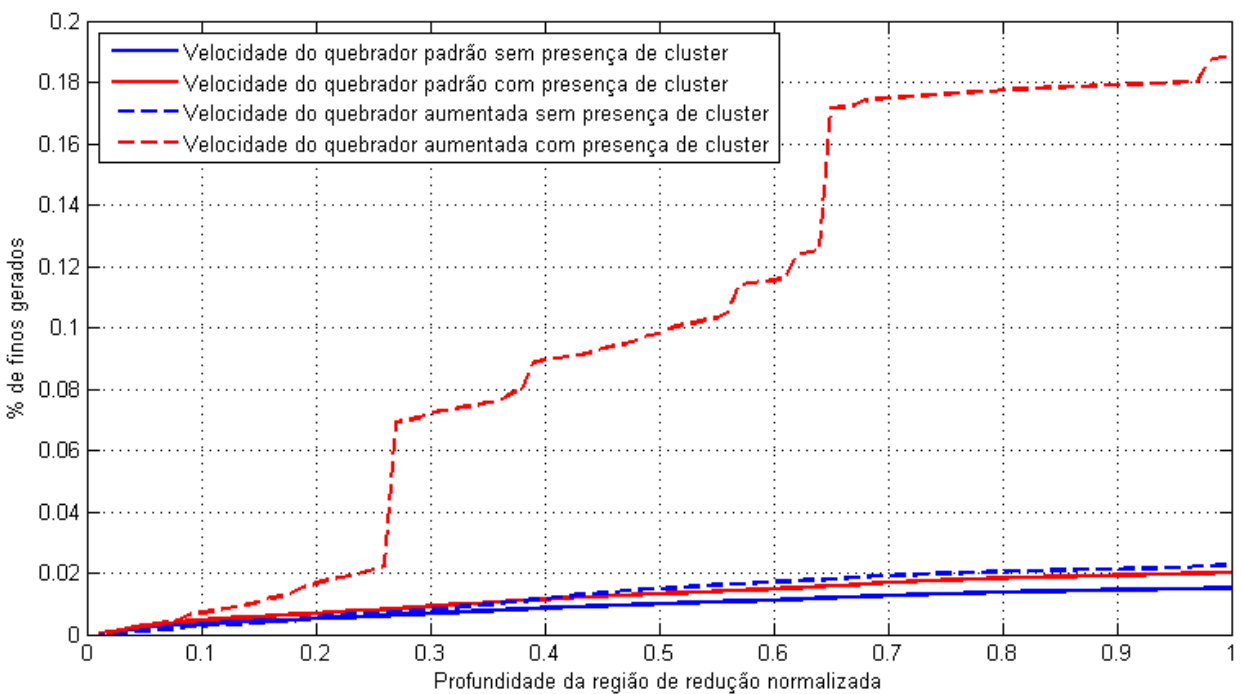

Figura 9 - Comparação da evolução da geração de finos em relação à profundidade do forno na região simulada com aumento do movimento do quebrador.

\section{CONCLUSÕES}

$\mathrm{Na}$ ausência de clusters na região do quebrador inferior no forno de redução Midrex as forças e energias de colisão provocadas pelo movimento dos quebradores seriam insuficientes para fragmentar pelotas. A presença de clusters, independentemente de 
seu tamanho é responsável pelo aumento da força compressiva e velocidade das pelotas em sua região.

A frequência de giro do quebrador, dentro dos níveis estudados, não afetou diretamente a magnitude das forças compressivas na região do quebrador inferior na ausência de clusters. Entretanto, esse aumento da frequência de giro do quebrador, aumentou tanto a magnitude das forças compressivas quanto a das velocidades das pelotas em sua região, na presença de clusters. Apesar de que a presença dos clusters ter aumentado a energia média das colisões das pelotas, não é possível afirmar que elas seriam suficientes para fragmenta-las por ser necessário usar valores comparativos de pelotas integras e sem a perda de resistência proveniente de sua redução. Entretanto é possivel perceber uma tendência de geração de finos quando há presença de cluster na região dos quebradores.

A presença de clusters e a variação da velocidade de giro do quebrador foram responsáveis pela criação de distúrbios no fluxo de material no interior do reator, podendo afetar negativamente a sua capacidade de produção além de mostrarem uma tendência maior da geração de finos.

\section{Agradecimentos}

Os autores agradecem à Vale S.A. pelo financiamento do estudo e pela autorização da sua publicação, enquanto L.M. Tavares e R.M. de Carvalho agradecem ao CNPq e à CAPES pelas bolsas de apoio à pesquisa.

\section{REFERÊNCIAS}

1 MIDREX. World direct reduction statistics. Midrex Technologies, Inc., p. 14, 2013.

2 Wong, P.L.M. et al. Sticking behaviour in direct reduction of iron ore. Ironmaking \& Steelmaking, v. 26, n. 1, p. 53-57, 1 jan. 1999.

3 BARRIOS, G. K. P. et al. Contact parameter estimation for dem simulation of iron ore pellet handling. Powder Technology, fev. 2013.

4 STANDARD, I. Iso 11256, 1998.

5 ATSUSHI, M.; UEMERA, H.; SAKAGUCHI, T. Midrex Process. Kobelco Technology Review, v. 29, p. 50 - 57, 2010.

6 HUANG, Z.; YI, L.; JIANG, T. Mechanisms of strength decrease in the initial reduction of iron ore oxide pellets. Powder Technology, v. 221, p. 284-291, maio. 2012.

7 TAVARES, L. M.; CARVALHO, R. M. DE. Modeling ore degradation during handling using continuum damage mechanics. International Journal of Mineral Processing, $v$. 101, n. 1-4, p. 21-27, nov. 2011.

8 BOECHAT, F. O.; CARVALHO, R. M.; BALTAZAR, A. W. S.; TAVARES, L. M. Simulação da degradação mecânica de pelotas de minério de ferro em forno de redução direta. $44^{\circ}$ Seminário de Redução de Minério de Ferro e Matérias-Primas \& $15^{\circ}$ Simpósio Brasileiro de Minério de Ferro. Anais.Belo Horizonte - MG. 2014. 